Supplement of Biogeosciences, 15, 2873-2889, 2018

https://doi.org/10.5194/bg-15-2873-2018-supplement

(C) Author(s) 2018. This work is distributed under

the Creative Commons Attribution 4.0 License.

(c) (1)

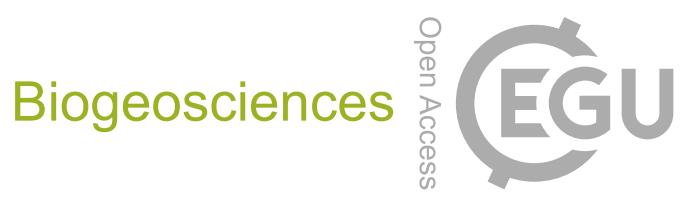

Supplement of

\title{
Short-term fate of intertidal microphytobenthos carbon under enhanced nutrient availability: a ${ }^{13} \mathrm{C}$ pulse-chase experiment
}

Philip M. Riekenberg et al.

Correspondence to: Philip M. Riekenberg (phrieken@gmail.com)

The copyright of individual parts of the supplement might differ from the CC BY 4.0 License. 


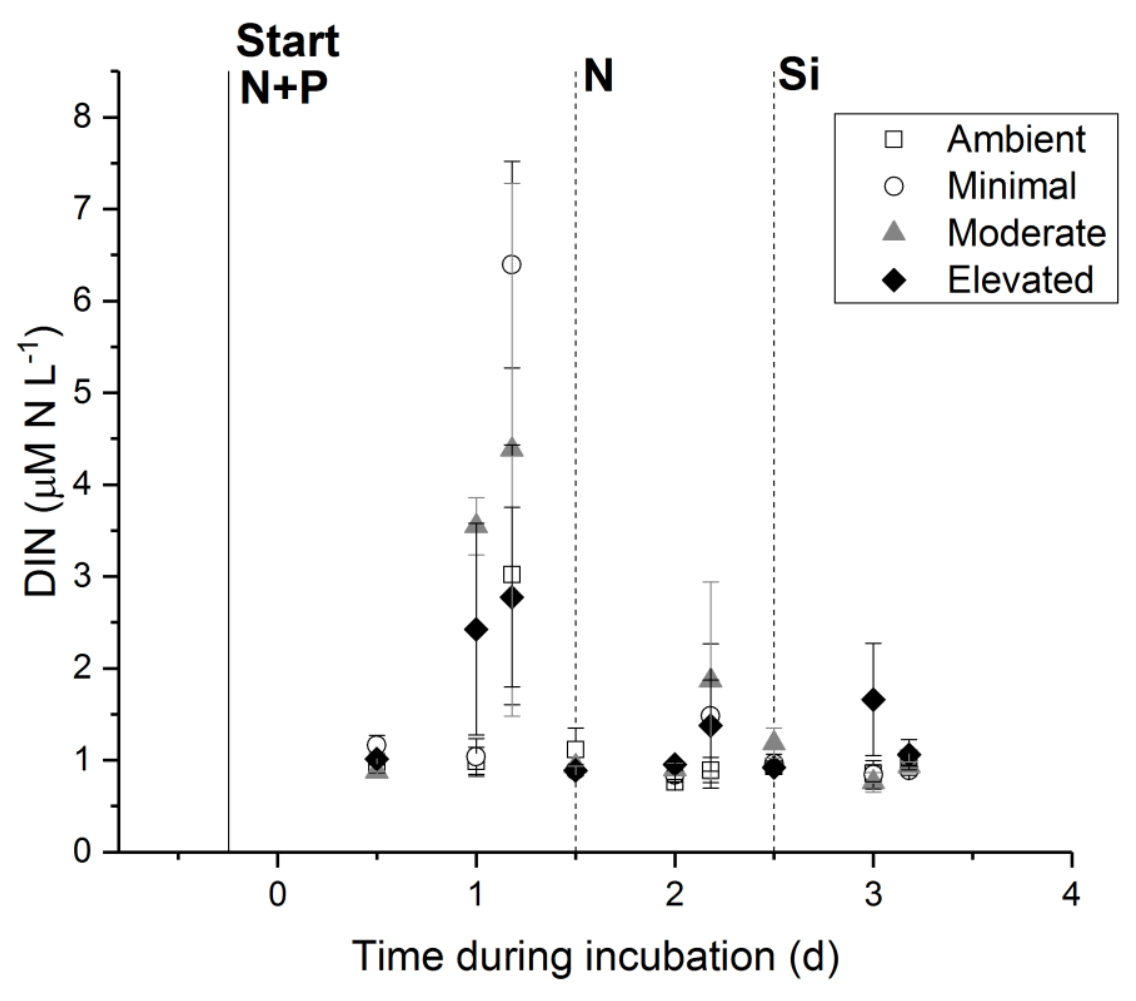

2

4 Supplemental Figure 1: Dissolved inorganic nitrogen in the overlying core waters during

5 sampling for light and dark incubations. The y-axis intercept represents the initial application of

$6 \mathrm{H}^{13} \mathrm{CO}_{3}$ to the sediment. The solid line is when cores were placed into treatment tanks prior to

7 the start of incubation. Dashed lines represent additional treatment pulses $\left(\mathrm{N}=\mathrm{NH}_{4}{ }^{+}, \mathrm{P}^{-} \mathrm{PO}_{4}{ }^{3-}\right.$,

$8 \mathrm{Si}=\mathrm{SiO}_{3}$ ) that occurred during incubation. 


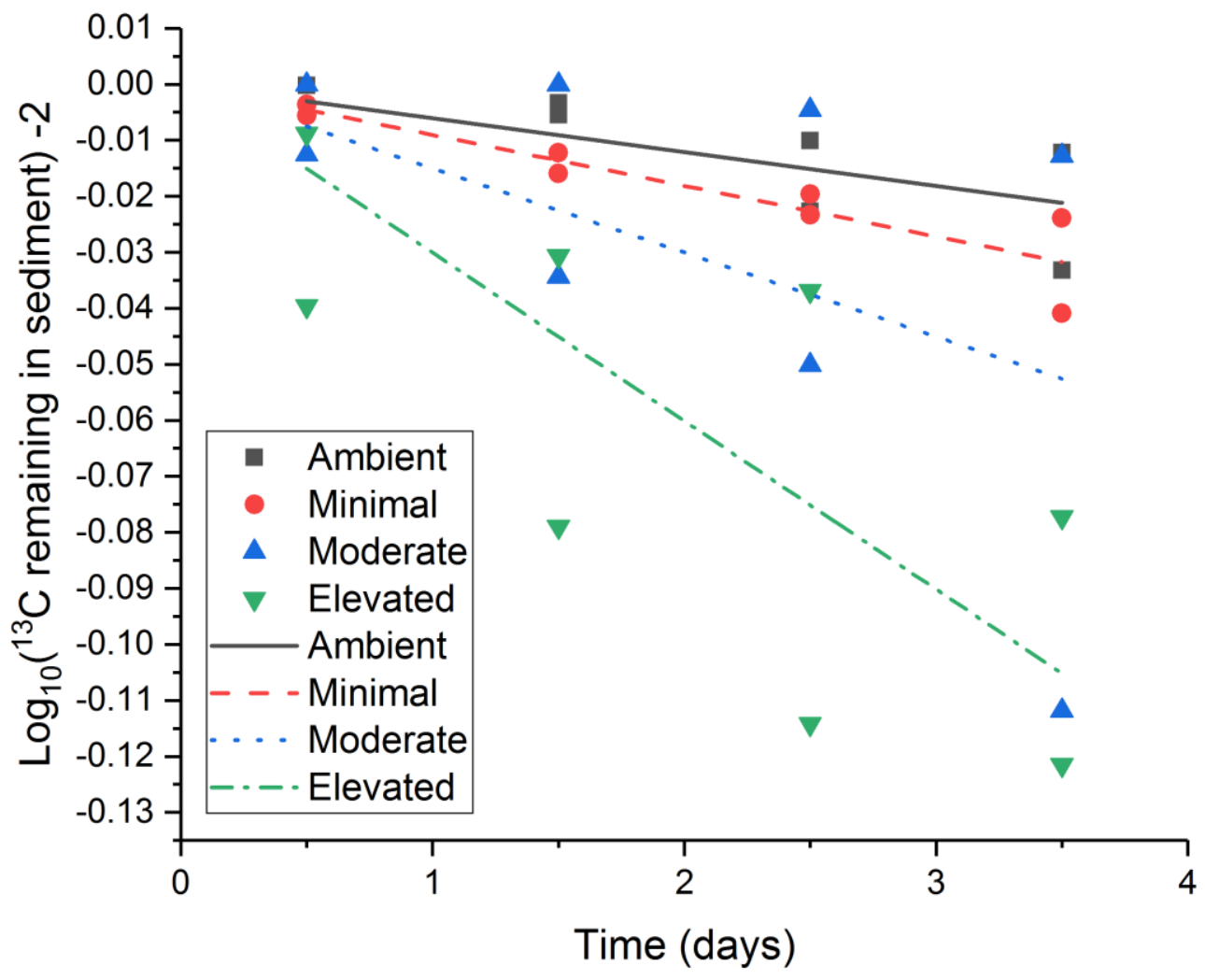

9

10 Supplemental Figure 2: Slope comparison between treatments for $\log _{10}$ transformed ${ }^{13} \mathrm{C}$

11 remaining in sediment. The model with different slopes for each treatment fitted significantly

12 better than the model with a single slope (F-test, $\left.F_{3,28}=9.84, \mathrm{P}<0.001\right)$.

13 


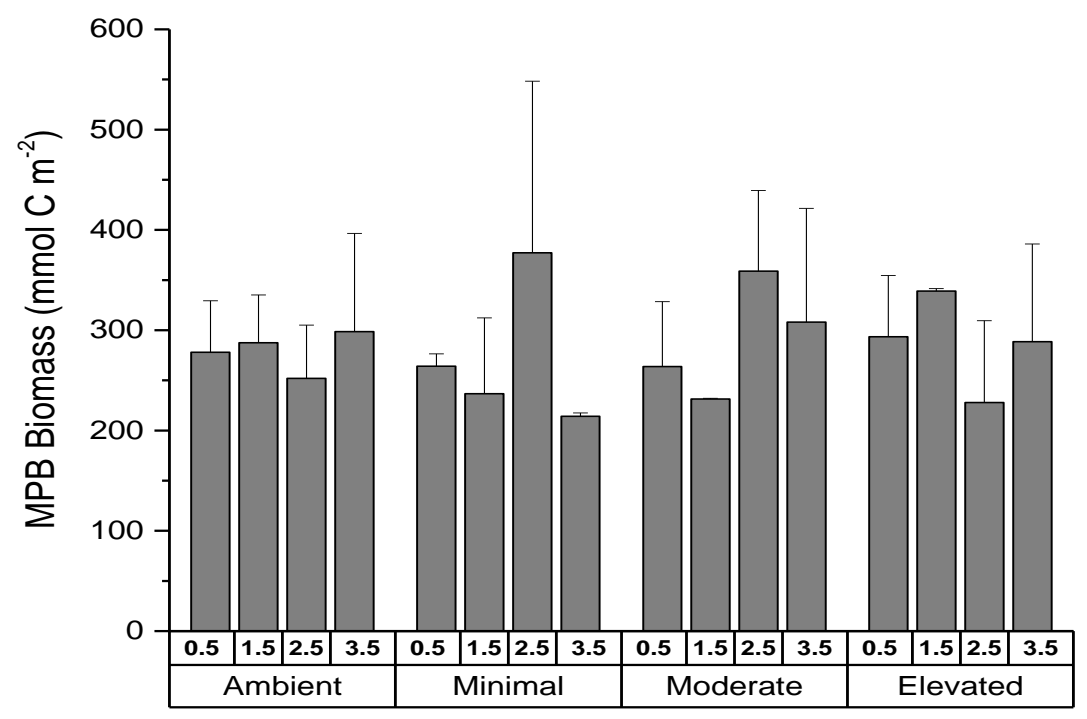

14

15 Supplemental Figure 3: MPB carbon biomass in 0 to $2 \mathrm{~cm}$ sediments calculated from

16 chlorophyll $a$ concentrations, assuming a C:Chl- $a$ ratio of 40 (mean $\pm \mathrm{SE}$ ).
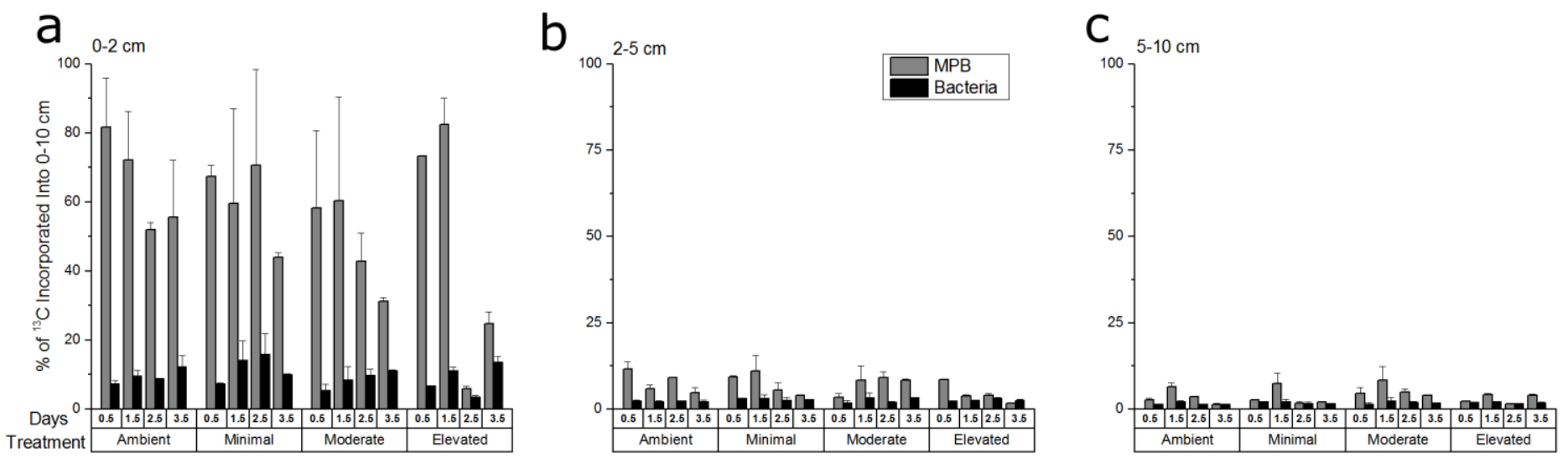

18 Supplemental Figure 4: Excess ${ }^{13} \mathrm{C}$ incorporation into MPB and bacterial biomass at depths a)

$190-2 \mathrm{~cm}$, b) $2-5 \mathrm{~cm}$ and c) $5-10 \mathrm{~cm}$ as a portion of the total ${ }^{13} \mathrm{C}$ in $0-10 \mathrm{~cm}$ sediment $\mathrm{OC}$ at each 20 time. 


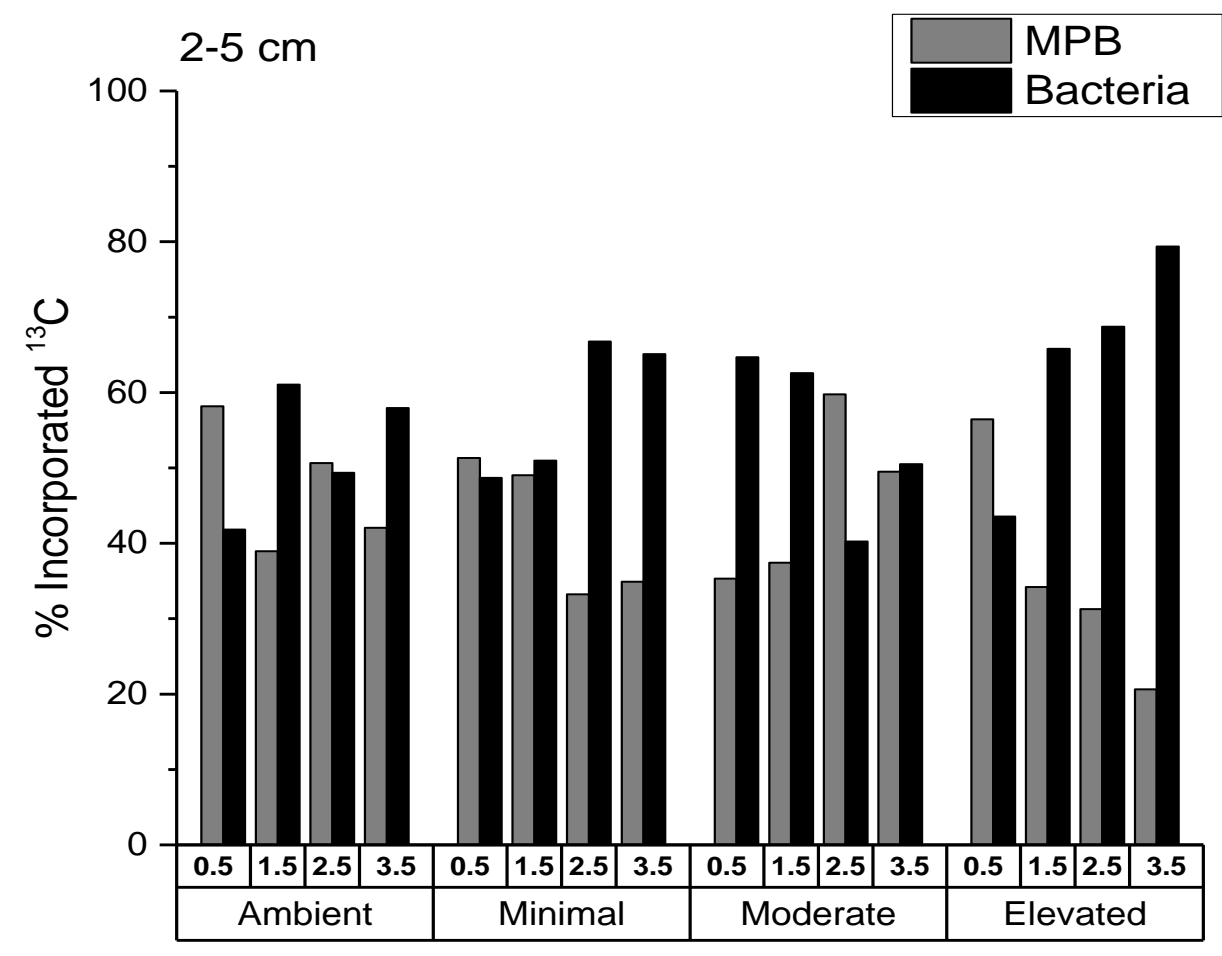

22 Supplemental Figure 5: Excess ${ }^{13} \mathrm{C}$ incorporation into MPB and bacterial biomass at a depth of

$23 \quad 2-5 \mathrm{~cm}$ as a percentage of the total ${ }^{13} \mathrm{C}$ in microbial biomass at $2-5 \mathrm{~cm}$ at each time period. There

24 are no error bars as PLFAs were analyzed for only one replicate sample from each time period. 


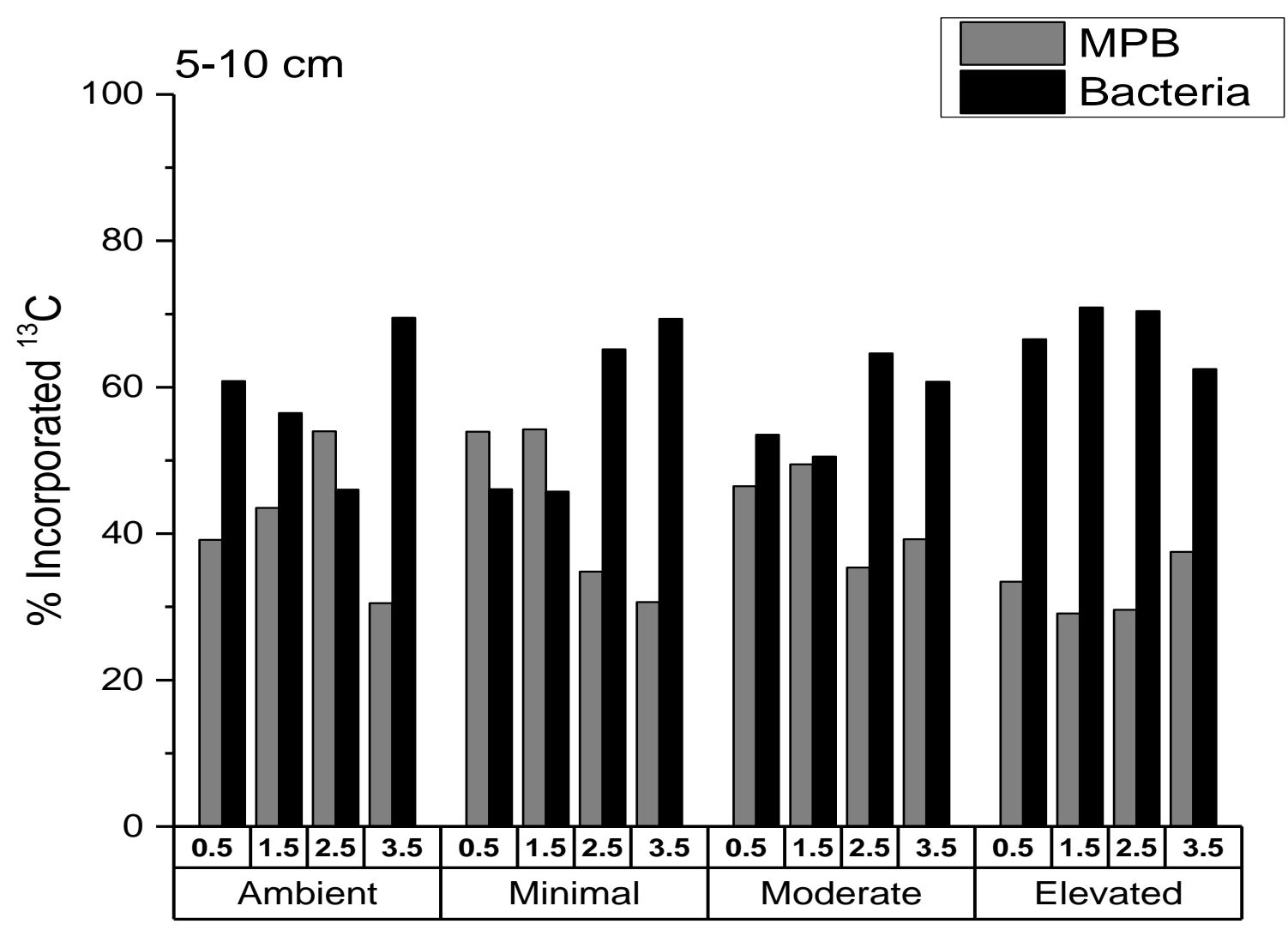

27 Supplemental Figure 6: Excess ${ }^{13} \mathrm{C}$ incorporation into MPB and bacterial biomass at a depth of

$285-10 \mathrm{~cm}$ as a percentage of the total ${ }^{13} \mathrm{C}$ in microbial biomass at $5-10 \mathrm{~cm}$ at each time period.

29 There are no error bars as PLFAs were analyzed for only one replicate sample from each time

30 period. 